\title{
A Contabilidade como Instrumento de Gestão dos Estabelecimentos Rurais ${ }^{1}$
}

\section{Accounting as a Management Tool for Rural Settlements \\ Contabilidad como instrumento de gestión para los Asentamientos Rurales}

\author{
Silvana Dalmutt kruger \\ Doutoranda em Contabilidade pela UFSC \\ Mestra em Contabilidade Universidade Comunitária da \\ Região de Chapecó \\ Rua Benjamin Galotti 260-D, Passo dos Fortes, CEP 89.805- \\ 060, Chapecó-SC, Brasil, Fone: (49)3323.9852 \\ e-mail: silvanak@unochapeco.edu.br

\section{Sady Mazzioni} \\ Doutorando em Ciências Contábeis e Administração pela \\ FURB e Mestre em Contabilidade \\ Bolsista do Programa do Fundo de Apoio à Manutenção e \\ ao Desenvolvimento da Educação Superior - FUMDES \\ Universidade Comunitária da Região de Chapecó \\ Rua Francisco Norberto Bonher, 55 E, Bairro Jardim Itália, \\ CEP 89.802-530, Chapecó-SC \\ Fone: (49) 9928 9520, e-mail: sady@unochapeco.edu.br
}

\author{
Ediane Glustak \\ Graduada em Ciências Contábeis \\ Universidade Comunitária da Região de Chapecó \\ Rua Senador Atílio Fontana, Bairro Efapi, CEP 89.809-000, \\ Chapecó-SC, Brasil. \\ Fone: (49) 3321.8243, e-mail: edianeg@unochapeco.edu.br
}

\section{RESUMO}

O objetivo do estudo é identificar o uso da contabilidade como instrumento de gestão das propriedades rurais. Os procedimentos metodológicos caracterizam a pesquisa como exploratória, de levantamento e de natureza quantitativa. Os dados foram coletados por meio de questionário com 150 produtores rurais do município de Erval Grande - RS. Constatou-se que a maioria das propriedades rurais é de pequeno porte, com até 50 hectares de terra e com a predominância da mão de obra familiar, em que o faturamento anual para $67 \%$ da amostra é de até $R \$ 24.000,00$. Verificou-se que $61 \%$ dos produtores rurais entrevistados não separam seus gastos particulares dos gastos com as atividades rurais. Para $56 \%$ dos entrevistados os preços dos produtos comercializados são definidos pela cooperativa ou empresa compradora e $48 \%$ desconhecem os objetivos e as finalidades da contabilidade. Os resultados gerais evidenciam a necessidade do reconhecimento dos objetivos da contabilidade pelos gestores rurais e da utilização da contabilidade como um instrumento de apoio à gestão das propriedades rurais, tendo em vista a carência identificada pelo estudo.

Palavras-chave: Contabilidade rural. Propriedades rurais. Gestão de estabelecimentos rurais.

\footnotetext{
1 Artigo recebido em 13.05.2014. Revisado pelos pares em 17.07.2014 (blind review). Ajustado e Aceito para publicação em 08.08.2014. Recomendado para publicação por Dr. José Ribamar Marques de Carvalho (Editor Científico). Publicado em 15.08.2014. Organização responsável UACC/CCJS/UFCG.
} 


\begin{abstract}
The objective of the study is to identify the use of accounting to management of rural properties. The methodological procedures characterized as exploratory research, survey and quantitative. Data were collected through a questionnaire with 150 farmers in the municipality of Herval Grande - RS. It was found that the majority of farms are small, with 50 acres of land and with the predominance of family labor, where the annual turnover to $67 \%$ of the sample is $R \$ 24.000,00$. It was found that $61 \%$ of farmers interviewed do not separate his private expenses of expenditure on rural activities. For $56 \%$ of respondents prices of traded goods are set by the cooperative or purchasing company and $48 \%$ are unaware of the goals and purposes of accounting. The overall results highlight the need for recognition of the objectives of accounting for land managers and the use of accounting as a tool to support the management of rural properties, in view of the shortage identified by the study.
\end{abstract}

KEYWORDS: Rural Accounting. Farms. Management of farms.

\title{
RESUMEN
}

El objetivo del estudio es identificar el uso de la contabilidad de la gestión de las propiedades rurales. Los procedimientos metodológicos caracterizados como la investigación exploratoria, el estudio y la naturaleza cuantitativa. Los datos fueron recolectados a través de un cuestionario con 150 agricultores en el municipio de Herbal Grande - RS. Se encontró que la mayoría de las explotaciones son pequeñas, con 50 acres de tierra y con el predominio de mano de obra familiar, donde el volumen de negocios anual de $67 \%$ de la muestra es de $\mathrm{R} \$$ $24.000,00$. Se encontró que el $61 \%$ de los agricultores entrevistados no separan su gasto el gasto privado en las actividades rurales. $56 \%$ de los encuestados en los precios de los bienes transables son establecidos por la empresa cooperativa o la compra y el $48 \%$ no son conscientes de los objetivos y propósitos de la contabilidad. Los resultados generales muestran la necesidad de reconocimiento de los objetivos de la contabilidad para los administradores de tierras y el uso de la contabilidad como una herramienta para apoyar la gestión de las propiedades rurales, en vista de la escasez identificados por el estudio.

Palabras clave: Contabilidad rural. Granjas. Gestión de las explotaciones.

\section{INTRODUÇÃO}

A participação do agronegócio na economia brasileira é representativa e importante para inúmeras atividades diretas e indiretas relacionadas ao agronegócio. O agronegócio representava $21,78 \%$ do Produto Interno Bruto (PIB) do Brasil em 2010, passando para 22,74\% do PIB em 2011, conforme o censo do Instituto Brasileiro de Geografia e Estatística - IBGE (2010).

Mendonça (2005) destaca a importância do agronegócio para a economia brasileira, contemplando a extração vegetal, a produção agrícola, as atividades zootécnicas e a comercialização e transportes desses produtos. A agricultura familiar também tem a sua participação na produção e movimentação do agronegócio no país. De acordo com o Ministério do Desenvolvimento Agrário - MDA (2012), a agricultura familiar é responsável pela produção de mais de dois terços dos alimentos consumidos no Brasil.

Mior (2005) salienta que o desenvolvimento rural do Brasil deve ter a reforma agrária e o fortalecimento da agricultura familiar como estratégia dos governantes. 
Sendo que além de convergir com o processo produtivo e econômico das agroindústrias, a agroindústria é responsável pela reprodução da agricultura familiar em várias atividades, entre elas destaca-se a criação de suínos, aves e também a atividade leiteira, realizadas em forma de parceria.

Neste contexto se insere a contabilidade rural, como instrumento de apoio, mensuração, controle e planejamento das atividades desenvolvidas no meio rural, visando atingir seu objetivo de controlar o patrimônio e possibilitar o acompanhamento dos resultados das atividades rurais e a análise dos investimentos realizados (CREPALDI, 2011; MARION, 2010).

Estudos anteriores, como os de Zanchet e Francischetti Junior (2006), Hofer, Borilli e Philippsen (2006), Mazzioni et. al (2007) e Calgaro e Faccin (2012), evidenciam a necessidade da utilização da contabilidade como instrumento de apoio para a análise e a gestão dos resultados das atividades desenvolvidas no meio rural.

No Rio Grande do Sul, 80,5\% do total de empregos gerados no campo são oriundos da agricultura familiar (MDA, 2012). O modelo da agricultura familiar se destaca por gerar renda para um maior número de brasileiros, é mais diversificada e ecologicamente sustentável. O município de Erval Grande fica localizado na região norte do Rio Grande do Sul, tem aproximadamente 5 mil habitantes e 37\% estão relacionados às atividades rurais (IBGE, 2010).

Neste contexto, surge a problemática da pesquisa: De que forma os produtores rurais do município de Erval Grande - RS, fazem uso da contabilidade no processo de gestão dos estabelecimentos rurais? Neste sentido, o estudo busca identificar as principais características do uso da contabilidade pelos estabelecimentos rurais do município de Erval Grande - RS.

Nesse sentido, o estudo se justifica pela importância de demonstrar o uso das informações contábeis como instrumento de apoio ao processo decisório pelos estabelecimentos rurais, visando o controle e o planejamento das atividades desenvolvidas, a mensuração e a análise dos resultados.

\section{FUNDAMENTAÇÃO TEÓRICA}

Neste capítulo abordam-se os conceitos e a abrangência da contabilidade rural, dos ativos biológicos e estudos correlatos relacionados à temática estudada. 


\subsection{Contextualização da contabilidade rural e a abordagem dos ativos biológicos}

O objeto da contabilidade é o patrimônio das entidades, independente se ele for resultado de consolidação, ou se for da subdivisão em parcelas menores que mereçam um acompanhamento nas suas variações e mutações, e ainda se é pessoa física ou jurídica (IUDÍCIBUS; MARION; FARIA, 2009).

Rodrigues et al. (2011) salienta que a contabilidade é uma importante aliada na tomada de decisões e é indispensável na administração moderna e na gestão de negócios. Então, a gestão das empresas, ou mesmo do patrimônio da pessoa física, deve levar em consideração os dados fornecidos pela contabilidade no momento da decisão.

Uma das questões mais importantes para Oliveira (2010) é saber que a contabilidade pode ser aplicada tanto para pessoas jurídicas como para pessoas físicas. A contabilidade rural, neste sentido, tem por objetivo o controle do patrimônio das entidades rurais. Crepaldi (2011) evidência entre as finalidades da contabilidade rural a orientação das operações realizadas no meio rural, medir o desempenho de cada atividade produtiva individualmente, apoiar o processo de decisões sobre investimentos, ou sobre a necessidade de recursos, controlar transações financeiras; permitir o comparativo de resultados, bem como, auxiliar no controle das despesas pessoais e nas informações para o imposto de renda.

As atividades desenvolvidas no meio rural podem ser divididas em atividades agrícolas, zootécnicas e agroindustriais. As atividades agrícolas são aquelas que exploram o cultivo e a produção vegetal. As atividades zootécnicas se referem à criação de animais, enquanto as atividades agroindustriais se referem ao beneficiamento e transformação de produtos agrícolas ou zootécnicos. (RODRIGUES, 2011; CREPALDI, 2011; MARION, 2010).

A contabilidade rural neste contexto está diretamente relacionada às entidades rurais e ao controle e planejamento das atividades desenvolvidas no meio rural, visando contribuir com a mensuração e análise dos resultados e no acompanhamento do desempenho individual dessas atividades (MARION, 2010; KRUGER et al., 2012).

A normatização das atividades desenvolvidas no meio rural também deve observar o Pronunciamento Técnico CPC 29, que trata dos Ativos Biológicos e Produtos Agrícolas. O CPC 29 (2009, p. 3) evidencia que "Ativo biológico é um animal e/ou uma planta, vivos", enquanto os produtos agrícolas são os resultantes da colheita ou das atividades zootécnicas. No Quadro 1 são apresentados alguns exemplos de ativos biológicos, produtos agrícolas e os resultantes do processamento após a colheita. 
Quadro 1: Ativos biológicos, produtos agrícolas e produtos resultantes do processamento após a colheita

\begin{tabular}{|l|l|l|}
\hline \multicolumn{1}{|c|}{ Ativos Biológicos } & \multicolumn{1}{|c|}{ Produtos agrícolas } & \multicolumn{1}{|c|}{$\begin{array}{c}\text { Produtos resultantes do processamento } \\
\text { após a colheita }\end{array}$} \\
\hline Carneiro & Lã & Fio, tapete \\
\hline Árvore de uma plantação & Madeira & Madeira serrada, celulose \\
\hline Plantas & $\begin{array}{l}\text { Algodão, Cana colhida, } \\
\text { Café }\end{array}$ & $\begin{array}{l}\text { Fio de algodão, roupa, açúcar, álcool, café } \\
\text { limpo em grão, café moído, café torrado }\end{array}$ \\
\hline Gado de leite & Leite & Queijo \\
\hline Porcos & Carcaça & Salsicha, presunto \\
\hline Arbustos & Folhas & Chá, tabaco \\
\hline Videiras & Uva & Vinho \\
\hline Árvores frutíferas & Frutas colhidas & Frutas processadas \\
\hline
\end{tabular}

Fonte: CPC (2009, p. 3).

O CPC 29 (2009, p. 5) ainda indica que "O ativo biológico deve ser mensurado ao valor justo menos a despesa de venda no momento do reconhecimento inicial e no final de cada período de competência." Neste sentido a entidade rural deve considerar, quando existir mercado ativo para determinado ativo biológico ou produto agrícola, o valor justo daquele mercado em que vai atuar, ou seja, utiliza o preço do mercado como valor justo, do local que se pretende vender.

Para Plais (2010, p. 9) “O ganho ou perda da mensuração do valor justo menos o custo de vender deverá ser registrado no resultado líquido do exercício, tendo como contrapartida a conta do ativo referente ao ativo biológico ou produto agrícola." Ainda, existem casos em que o valor justo não pode ser identificado de maneira confiável na mensuração do ativo biológico. Para essas situações, Iudícibus et al. (2010, p. 235) definem que "o ativo biológico deve ser mensurado pelo custo deduzidas a depreciação acumulada e as perdas acumuladas por redução ao valor recuperável".

Para as entidades em que o valor justo não pode ser mensurado de forma confiável, a divulgação deve contemplar: (i) a justificativa do valor justo não poder ser mensurado de forma confiável, (ii) a descrição do ativo biológico, (iii) qual o método adotado para a depreciação e sua taxa, (iv) a vida útil, (v) o total bruto e a depreciação acumulada desde o início até o fim do período, e, (vi) as estimativas utilizadas para encontrar o valor justo (CPC 29, 2009).

Salienta-se que, as novas exigências relacionadas à mensuração, avaliação e evidenciação dos ativos biológicos, também afetam as entidades rurais e indica a necessidade da contabilidade ser utilizada como instrumento de apoio, não somente para o processo de análise e gestão dos resultados, mas também para possibilitar a elaboração de informações que atendam as novas normas de contabilidade (CPC 29, 2009; PLAIS, 2010). 
Dessa forma, os gestores dos estabelecimentos ou entidades rurais devem buscar maximizar os resultados das atividades desenvolvidas e observar as orientações das normativas contábeis. A contabilidade, neste contexto, torna-se instrumento de apoio para a mensuração e controle dos resultados das atividades, identificando a rentabilidade e o desempenho por atividade (CREPALDI, 2011; MARION, 2010).

\subsection{Estudos correlatos à temática estudada}

Zanchet e Francischetti Junior (2006) analisaram o perfil contábiladministrativo dos produtores de Marechal Cândido Rondon, associados à ACEMPRE - Associação Central dos Produtores Ecológicos, visando identificar o nível de utilização e potencialidades de implementação de modelos gerenciais para a tomada de decisões nas propriedades. A metodologia adotada é exploratória, caracterizando-se como um levantamento, com a aplicação de questionário a 28 produtores rurais. Os resultados obtidos demonstram que os produtores baseiam-se em suas experiências para o gerenciamento dos negócios. Além disso, não fazem nenhuma separação dos gastos particulares dos gastos dos negócios rurais, nem mesmo separam os gastos e despesas de cada atividade. A pesquisa ainda revelou que a maioria dos produtores rurais fazem suas próprias anotações em "caderninhos" para a tomada de decisões, porém a grande maioria deles demonstrase interessado em participar de cursos da área contábil-administrativa reconhecendo, assim, a importância desta área para o desenvolvimento das atividades.

Hofer, Borilli e Philippsen (2006) realizaram uma pesquisa em um município no estado do Paraná, com o objetivo de mostrar a importância da contabilidade rural para o pequeno, médio e grande produtor rural, ou seja, como é vista a ferramenta gerencial que auxilia por meio de informações contábeis, no planejamento e na tomada de decisões, permitindo, assim, na diversificação de culturas e na modernização do setor. Para que este objetivo fosse alcançado, foi realizada uma pesquisa de campo, com questionários/entrevistas aplicados a 21 gerentes de escritórios de contabilidade e a 262 proprietários. Os resultados indicam que a contabilidade é uma ferramenta pouco utilizada, sendo utilizada para fins fiscais e não como ferramenta administrativa. A pesquisa também revelou pouco interesse dos proprietários rurais utilizarem a contabilidade gerencial para auxiliar na tomada de decisões. Os profissionais mostraram-se interessados em fazer a contabilidade rural, mas admitem a existência de carências de qualificação para atuar nesta ramificação contábil. Assim, a contabilidade rural mostra-se como um campo de atuação que pode ser explorado pelos contadores, pelas oportunidades existentes. 
O estudo de Mazzioni et al. (2007) teve por objetivo analisar se os proprietários rurais fazem o uso da contabilidade para o controle gerencial das suas atividades. A coleta dos dados considerou a aplicação de questionário para cem empresas rurais pertencentes à região de abrangência da Secretaria de Desenvolvimento Regional de Chapecó - SC. Esta pesquisa revelou que pequenos e médios proprietários rurais não valorizam a contabilidade como ferramenta de gestão, ou até desconhecem, e que vários deles não fazem anotações para que delas sejam tomadas decisões. Além disso, não segregam as despesas próprias com as despesas do agronegócio.

O estudo de Clemente et al. (2010) teve por objetivo examinar os controles de custos na agricultura familiar da região Centro-Sul do Paraná e buscar relações, se existentes, entre o perfil socioeconômico das propriedades e os controles de diversos custos. Para isso, foi aplicado um questionário em 235 propriedades rurais. Este estudo concluiu que os controles dos diversos tipos de custos não são criteriosos, e, ainda, precários. Aliado a isso, a informação gerencial é escassa e dificulta a tomada de decisões, considerando que a gestão é praticamente familiar.

Calgaro e Faccin (2012) realizaram uma pesquisa com proprietários rurais do $3^{\circ}$ Distrito de Flores da Cunha, com o objetivo de analisar a real situação dos controles gerenciais dessas propriedades, apontando as principais características da ferramenta, adequando-as à realidade do agronegócio. Ainda, teve a estruturação de um fluxo de caixa rural com o fim de identificar as entradas e saídas de caixa e, também, identificar as despesas de cada atividade proporcionando maior controle dos dados apresentados. Para a realização desta pesquisa, foram interrogados 13 proprietários rurais que desempenham atividade familiar, correspondendo a $22 \%$ da população. A metodologia desta pesquisa foi análise exploratória a partir de estudo de caso. Os resultados demonstraram que a maioria dos proprietários rurais não faz o uso de ferramentas de controles, principalmente pela falta de conhecimento. $\mathrm{O}$ controle encontrado foram cadernos de campo elaborados em cursos. A pesquisa também revelou que os proprietários rurais possuem interesse em implantar controles, desde que fossem de baixa complexidade e baixo custo.

O estudo de Dorr (2012) tem o objetivo de analisar a utilização de instrumentos de gestão contábil pelos produtores agropecuários visitantes na feira agropecuária de Santa Maria - RS, no ano de 2010. Para a realização do estudo, foram entrevistados 21 produtores rurais que utilizam máquinas agrícolas, escolhidos aleatoriamente para responder aos questionários semiestruturados. $\mathrm{O}$ resultado deste estudo aponta que como meio de controle das atividades, os produtores utilizam-se da guarda de recibos e notas fiscais, não gerando ferramentas para a tomada de decisões. Mais da metade dos produtores pesquisados separam os custos de produção, e os que separam estes custos são os produtores que possuem área de até 
100 hectares. Os resultados também constatarem que a maioria dos produtores rurais utiliza controle de estoque de insumos, produtos, peças e combustíveis. Os autores ainda salientam que é preciso incentivar os produtores a realizarem cursos de aperfeiçoamento em técnicas gerenciais e que haja um apoio dos profissionais contábeis para mostrar que as ferramentas geradas pela contabilidade são úteis no processo decisório.

\section{PROCEDIMENTOS METODOLÓGICOS}

De acordo com o Censo Demográfico do IBGE (2010), o município de Erval Grande (RS) possui 5.167 habitantes, destes 2.800 vivem na zona urbana e 2.367 na zona rural. Na zona rural existem 850 propriedades rurais, de acordo com a Associação Riograndense de Empreendimentos de Assistência Técnica e Extensão Rural - Emater (2012). A amostra do estudo é composta por 150 propriedades rurais, escolhidas de forma aleatória.

Metodologicamente a pesquisa se caracteriza como exploratória, pois visa identificar as principais características das propriedades rurais do Município de Erval Grande - RS. Quanto aos procedimentos, é caracterizada como um levantamento, com aplicação de um questionário de pesquisa aos gestores rurais. E a análise dos dados é tratada de forma quantitativa a partir das respostas do questionário aplicado.

Visando atingir aos objetivos propostos pelo estudo, foi realizada uma pesquisa com perguntas abertas e fechadas e aplicados a 150 proprietários rurais do Município pesquisado. O questionário de pesquisa aplicado foi adaptado do modelo de Klein (2005).

Após a organização dos dados, foram elaboradas tabelas, com o intuito de facilitar a compreensão do assunto e permitir a comparação e análise dos resultados da pesquisa.

\section{APRESENTAÇÃO E DISCUSSÃO DOS RESULTADOS}

A partir da coleta de dados realizada por meio da aplicação de questionários buscou-se identificar as principais características das propriedades rurais do município de Erval Grande - RS, em relação à utilização da contabilidade.

Inicialmente buscou-se identificar qual a extensão de terras ou tamanho que cada produtor rural entrevistado do município de Erval Grande possui. As respostas coletadas estão demonstradas na Tabela 1. 
Tabela 1 - Tamanho das propriedades rurais

Entre 1 e 15 hectares Tamanho

Entre 15 e 25 hectares

Entre 25 e 50 hectares

Entre 50 e 75 hectares

Acima de 75 hectares

Fonte: Dados da pesquisa

Na Tabela 1, observa-se que 55\% dos proprietários rurais entrevistados possuem entre 1 e15 hectares de terra. Entre 15 e 25 hectares encontram-se $27 \%$ dos produtores rurais. E apenas $18 \%$ dos produtores rurais possuem mais de 25 hectares de terra. Observa-se que $96 \%$ dos produtores rurais pesquisados possuem propriedades de pequeno porte com até 50 hectares, sendo que destes, $82 \%$ possuem até 25 hectares.

Os resultados do questionamento sobre a área de terras cultivada pelos produtores rurais são apresentados na Tabela 2, a qual evidencia que, apesar de alguns produtores rurais possuírem áreas maiores que 50 hectares, cultivam, no máximo, 50 hectares. A maioria dos produtores entrevistados $(80 \%)$ cultivam entre 1 e 15 hectares e $15 \%$ entre 15 e 25 hectares. Outros $5 \%$ dos produtores rurais cultivam entre 25 e 50 hectares.

Tabela 2 - Área cultivada nas propriedades rurais

\begin{tabular}{l|c|c}
\hline \multicolumn{1}{c|}{ Tamanho } & Frequência Absoluta & Frequência Relativa (\%) \\
\hline Entre 1 e 15 hectares & 120 & 80 \\
Entre 15 e 25 hectares & 23 & 15 \\
Entre 25 e 50 hectares & 7 & 5 \\
Entre 50 e 75 hectares & 0 & 0 \\
Acima de 75 hectares & 0 & 0 \\
\hline Total & 150 & 100 \\
\hline
\end{tabular}

Fonte: Dados da pesquisa

Os entrevistados foram questionados sobre as atividades desenvolvidas no meio rural e os resultados estão dispostos na Tabela 3.

Tabela 3 - Atividades desenvolvidas no meio rural

\begin{tabular}{l|c|c}
\hline \multicolumn{1}{c|}{ Atividades } & Frequência Absoluta & Frequência Relativa (\%) \\
\hline Milho & 124 & 12 \\
Soja & 51 & 5 \\
Feijão & 65 & 6 \\
Trigo & 4 & 0 \\
Hortaliças e verduras & 102 & 10 \\
Frutas & 103 & 10 \\
Reflorestamento & 61 & 6
\end{tabular}




\begin{tabular}{l|c|c} 
Suinocultura & 60 & 6 \\
Bovinocultura de leite & 94 & 9 \\
Bovinocultura de corte & 75 & 7 \\
Ovinocultura & 9 & 1 \\
Avicultura & 64 & 6 \\
Fumo & 35 & 3 \\
Conservas & 33 & 3 \\
Queijo & 59 & 6 \\
Salame & 53 & 5 \\
Videira & 6 & 1 \\
Mel & 1 & 0 \\
Equinocultura & 2 & 0 \\
\hline Total & 1001 & 100 \\
\hline
\end{tabular}

Fonte: Dados da pesquisa

Os resultados apresentados na Tabela 3 evidenciam que a atividade mais cultivada é o milho (12\%), seguido pelas hortaliças e verduras e pelas frutas $(10 \%)$. A bovinocultura de leite aparece com $9 \%$ e a de corte com $7 \%$. Em seguida aparece o feijão, reflorestamento, suinocultura, avicultura e a produção de queijo, ambos com 6\%. Dos 150 respondentes foram obtidas 1.001 respostas de atividades desenvolvidas. Estes resultados indicam uma diversidade de atuação, em que os produtores não se concentram em monocultura, permitindo, inclusive produção ecologicamente mais adequada.

Outro fator aplicado na pesquisa foi referente ao número de pessoas da família e de terceiros que trabalham na propriedade rural. $O$ resultado é apresentado na Tabela 4.

Tabela 4 - Trabalhadores na empresa rural.

\begin{tabular}{l|c|c}
\hline \multicolumn{1}{c|}{ Trabalhadores da Família } & Frequência Absoluta & Frequência Relativa (\%) \\
\hline Até 3 pessoas & 124 & 83 \\
De 3 a 5 pessoas & 23 & 15 \\
Acima de 5 pessoas & 3 & 2 \\
\hline Total & 150 & 100 \\
\hline \multicolumn{1}{c}{ Trabalhadores Contratados } & Frequência Absoluta & Frequência Relativa (\%) \\
\hline Não há & 116 & 21 \\
Até 2 pessoas & 31 & 2 \\
Acima de 2 pessoas & 3 & 100 \\
\hline Total & 150 & 27 \\
\hline
\end{tabular}

Fonte: Dados da pesquisa

Os resultados da Tabela 4 indicam que $83 \%$ das propriedades rurais possuem até 3 trabalhadores da família, 15\% das propriedades possuem de 3 a 5 pessoas e somente $2 \%$ possuem mais que 5 pessoas da família trabalhando na propriedade. Em relação aos terceiros, $21 \%$ das propriedades rurais possuem até 2 pessoas 
contratadas, $2 \%$ possuem mais de 2 contratados, e outras $77 \%$ das propriedades rurais não possuem nenhum trabalhador contratado na sua propriedade rural.

A Tabela 5 apresenta o vínculo que os terceirizados possuem com a entidade rural.

Tabela 5 - Vínculo empregatício com a empresa rural

\begin{tabular}{l|c|c}
\hline \multicolumn{1}{c|}{ Vínculo Empregatício } & Frequência Absoluta & Frequência Relativa (\%) \\
\hline Contratos eventuais & 28 & 82 \\
Contratos permanentes & 6 & 18 \\
\hline Total & 34 & 100 \\
\hline
\end{tabular}

Fonte: Dados da pesquisa

Na Tabela 5 observa-se que $82 \%$ dos trabalhadores são contratados nas entidades rurais de modo eventual, isto é, somente quando há necessidade pelos serviços, e apenas $18 \%$ são trabalhadores fixos das propriedades rurais.

Sobre o faturamento bruto anual, os resultados são demonstrados na Tabela 6.

Tabela 6 - Faturamento bruto anual

\begin{tabular}{l|c|c}
\hline \multicolumn{1}{c|}{ Faturamento } & Frequência Absoluta & Frequência Relativa (\%) \\
\hline Até $\mathrm{R} \$ 12.000,00$ & 50 & 33 \\
De $\mathrm{R} \$ 12.001,00$ até $\mathrm{R} \$ 24.000,00$ & 51 & 34 \\
De $\mathrm{R}$ \$ 24.001,00 até $\mathrm{R}$ \$ 48.000,00 & 28 & 19 \\
De $\mathrm{R}$ 48.001,00 até $\mathrm{R}$ \$ 80.000,00 & 17 & 11 \\
Acima de $\mathrm{R}$ 80.000,00 & 4 & 3 \\
\hline Total & 150 & 100 \\
\hline
\end{tabular}

Fonte: Dados da pesquisa

Em relação ao faturamento bruto anual percebe-se que 33\% dos entrevistados responderam que possuem o faturamento de até $\mathrm{R} \$ 12.000,00 ; 34 \%$ faturam anualmente entre $\mathrm{R} \$ 12.000,00$ e $\mathrm{R} \$ 24.000,00$. Outros $19 \%$ apresentaram o faturamento entre $\mathrm{R} \$ 24.000,00$ e $\mathrm{R} \$ 48.000,00$, e apenas $14 \%$ têm faturamento acima de $\mathrm{R} \$ 48.000,00$.

Outro questionamento feito aos entrevistados refere-se à separação das despesas particulares dos gastos com a atividade rural, conforme a Tabela 7.

Tabela 7 - Separação das despesas particulares daquelas do negócio agropecuário

\begin{tabular}{l|c|c}
\hline \multicolumn{1}{c|}{ Separação } & Frequência Absoluta & Frequência Relativa (\%) \\
\hline Sim & 58 & 39 \\
Não & 92 & 61 \\
\hline Total & 150 & 100 \\
\hline
\end{tabular}

Fonte: Dados da pesquisa

A Tabela 7 demonstra que a maioria dos produtores rurais de Erval Grande RS não separam as despesas particulares das despesas com a atividade rural, ou seja, $61 \%$ dos entrevistados responderam que não fazem este controle. Apenas 39\% dos entrevistados separam as suas despesas da do agronegócio. 
A pesquisa também buscou identificar se os produtores rurais pesquisados possuem anotações simples, como cálculos de custos, anotações sobre as despesas, cálculos sobre quanto precisa investir para o plantio, entre outros, para a tomada de decisões, conforme Tabela 8.

Tabela 8 - Anotações que auxiliam na tomada de decisões

\begin{tabular}{l|c|c}
\hline \multicolumn{1}{c|}{ Anotações } & Frequência Absoluta & Frequência Relativa (\%) \\
\hline Sim & 79 & 52 \\
Não & 67 & 45 \\
Possuem anotações organizadas em planilhas & 4 & 3 \\
\hline Total & 150 & 100 \\
\hline
\end{tabular}

Fonte: Dados da pesquisa

Observa-se na Tabela 8 que 52\% dos entrevistados afirmaram que possuem alguma anotação para auxiliar na tomada de decisões e $45 \%$ não possuem nenhuma anotação. Outros 3\% dos entrevistados indicaram que possuem anotações organizadas em planilhas.

A Tabela 9 apresenta o conhecimento que os produtores rurais possuem dos custos de cada unidade produzida.

Tabela 9 - Conhecimento do custo de cada unidade

\begin{tabular}{l|c|c}
\hline \multicolumn{1}{c|}{ Sabe o custo de cada unidade } & Frequência Absoluta & Frequência Relativa (\%) \\
\hline Sim & 92 & 61 \\
Não & 58 & 39 \\
\hline Total & 150 & 100 \\
\hline
\end{tabular}

Fonte: Dados da pesquisa

Observa-se que $61 \%$ dos entrevistados disseram conhecer o custo de cada unidade produzida em suas propriedades rurais e 39\% alegam não ter conhecimento, conforme evidencia a Tabela 9.

Em relação ao processo de formação dos preços de vendas, os entrevistados foram questionados se definem os preços de venda dos produtos a serem comercializados, ou se possuem influência externa, como o valor informado pelo sindicato, oferecido pela cooperativa ou empresa compradora, ou de forma geral definido pelo mercado comprador dos seus produtos, cujos resultados são apresentados na Tabela 10.

Tabela 10 - Definição do preço de venda

\begin{tabular}{l|c|c}
\hline \multicolumn{1}{c|}{ Preço de Venda } & Frequência Absoluta & Frequência Relativa (\%) \\
\hline Pelo valor informado pelo sindicato & 8 & 5 \\
Pelo valor oferecido pela cooperativa ou & 84 & 56 \\
O produtor rural o define & 11 & 7 \\
Pelo valor oferecido pelo mercado & 47 & 31 \\
\hline Total & 150 & 100 \\
\hline
\end{tabular}

Fonte: Dados da pesquisa 
O preço de venda mais representativo na pesquisa é aquele oferecido pela cooperativa ou empresa compradora com 56\% das respostas, em seguida aparece o preço oferecido pelo mercado com $31 \%$. O valor definido pelo próprio produtor rural teve $7 \%$ das respostas dos entrevistados e a definição pelo sindicato foi indicado por $5 \%$ dos respondentes.

Os produtores também foram questionados se conhecem ou não o lucro das suas atividades, conforme a Tabela 11.

Tabela 11 - Lucro das atividades

\begin{tabular}{l|c|c}
\hline \multicolumn{1}{c|}{ Conhecimento do Lucro } & Frequência Absoluta & Frequência Relativa (\%) \\
\hline Sim & 124 & 83 \\
Não & 26 & 17 \\
\hline Total & 150 & 100 \\
\hline
\end{tabular}

Fonte: Dados da pesquisa

Dos produtores rurais entrevistados, $83 \%$ admitem conhecer o lucro de suas atividades e apenas $17 \%$ admitem não saber ou não conhecer o lucro das atividades.

Buscou-se identificar se algum órgão proporciona treinamentos para a qualificação das atividades desenvolvidas no meio rural. O resultado é apresentado na Tabela 12.

Tabela 12 - Treinamentos realizados para a qualificação das atividades desenvolvidas

\begin{tabular}{l|c|c}
\multicolumn{1}{c|}{ Treinamentos } & Frequência Absoluta & Frequência Relativa (\%) \\
\hline Sim & 108 & 72 \\
Não & 42 & 28 \\
\hline Total & 150 & 100 \\
\hline
\end{tabular}

Fonte: Dados da pesquisa

Conforme a Tabela 12, 72\% dos entrevistados responderam que têm algum órgão que realiza treinamentos para a qualificação das atividades desenvolvidas, e $28 \%$ deles afirmaram não receber treinamentos. A Tabela 13 mostra os organismos que proporcionam os treinamentos para a qualificação das atividades desenvolvidas pelos produtores rurais.

Tabela 13 - Órgãos que proporcionam treinamentos

\begin{tabular}{l|c|c}
\hline \multicolumn{1}{c|}{ Órgão que Proporciona Treinamentos } & Frequência Absoluta & Frequência Relativa (\%) \\
\hline Emater & 59 & 30 \\
Prefeitura & 15 & 8 \\
Senar & 7 & 4 \\
Sindicato & 29 & 15 \\
Cooperativa/Empresa & 84 & 42 \\
Sebrae & 2 & 1 \\
\hline Total & 196 & $100 \%$ \\
\hline
\end{tabular}

Fonte: Dados da pesquisa 
Pelos resultados da Tabela 13 é possível perceber que as Cooperativas/Empresas são os organismos que mais proporcionam treinamentos (42\%) aos entrevistados. Em seguida, aparece a Emater com 30\% das respostas e o Sindicato com 15\%. Depois de identificados os órgãos que proporcionam treinamentos, buscou-se identificar qual era a finalidade destes treinamentos, com os resultados sendo apresentados na Tabela 14.

Tabela 14 - Finalidades dos treinamentos

\begin{tabular}{l|c|c}
\hline \multicolumn{1}{c|}{ Finalidade do Treinamento } & Frequência Absoluta & Frequência Relativa (\%) \\
\hline Melhorar a produtividade de sua empresa rural & 70 & $38 \%$ \\
Destinado a industrialização de produtos & 7 & $4 \%$ \\
Melhorar a qualidade de vida da empresa rural & 66 & $36 \%$ \\
Melhor gestão, controle e administração & 37 & $20 \%$ \\
Outros & 3 & $2 \%$ \\
\hline Total & 183 & $100 \%$ \\
\hline
\end{tabular}

Fonte: Dados da pesquisa

A Tabela 14 evidencia que $38 \%$ dos treinamentos são destinados a melhorar a produtividade da propriedade rural, $36 \%$ se destinam a melhorar a qualidade de vida da empresa rural e $20 \%$ estão destinados a melhorar a gestão, controle e administração da empresa rural. Os entrevistados foram questionados a respeito da utilização de consultoria nas propriedades rurais, e nos casos em que utilizam identificou-se o tipo de consultoria, conforme apresentado na Tabela 15.

Tabela 15 - Utilização e tipo de consultoria

\begin{tabular}{l|c|c}
\hline \multicolumn{1}{c|}{ Utilização de Consultoria } & Frequência Absoluta & Frequência Relativa (\%) \\
\hline Sim & 37 & 25 \\
Não & 113 & 75 \\
\hline Total & 150 & 100 \\
\hline
\end{tabular}

\begin{tabular}{l|c|c}
\hline Tipo de Consultoria & Frequência Absoluta & Frequência Relativa (\%) \\
\hline Advogado & 1 & 3 \\
Contador & 2 & 5 \\
Agente da cooperativa & 20 & 51 \\
Engenheiro agrônomo & 12 & 31 \\
Técnico Agrícola & 2 & 5 \\
Veterinário & 2 & 5 \\
\hline Total & 39 & 100 \\
\hline
\end{tabular}

Fonte: Dados da pesquisa

Identifica-se pela Tabela 15 que $75 \%$ dos entrevistados não utilizam nenhum tipo de consultoria. E, entre os $25 \%$ que utilizam, destaca-se o serviço do agente da cooperativa com $51 \%$, seguido pelo engenheiro agrônomo com $31 \%$, e o contador 
aparece com 5\%. Nota-se que o produtor rural reconhece em pouca frequência a importância do profissional contábil na gestão de sua atividade econômica.

Em seguida, buscou-se identificar se a consultoria prestada é remunerada.

Tabela 16 - Consultoria remunerada

\begin{tabular}{l|c|c}
\hline Consultoria Remunerada & Frequência Absoluta & Frequência Relativa (\%) \\
\hline Sim & 8 & 22 \\
Não & 29 & 78 \\
\hline Total & 37 & 100 \\
\hline
\end{tabular}

Fonte: Dados da pesquisa

A Tabela 16 demonstra que a maioria dos entrevistados (78\%) não paga pela consultoria prestada em sua propriedade e apenas $22 \%$ remunera o serviço prestado. Os proprietários rurais entrevistados indicaram qual a finalidade da contabilidade, em que os resultados estão dispostos na Tabela 17.

Tabela 17 - Finalidade da contabilidade

\begin{tabular}{l|c|c}
\hline Finalidade da Contabilidade & Frequência Absoluta & Frequência Relativa (\%) \\
\hline Prestar contas ao fisco & 24 & 16 \\
Auxiliar no processo de gestão & 54 & 36 \\
Desconhece suas finalidades & 72 & 48 \\
\hline Total & 150 & 100 \\
\hline
\end{tabular}

Fonte: Dados da pesquisa

Conforme a Tabela 17, 48\% dos entrevistados desconhecem a finalidade da Contabilidade e $36 \%$ indicaram que a finalidade é fornecer informações para auxiliar no processo de gestão das empresas e 16\% ainda acreditam que a contabilidade é apenas para fins de prestar contas ao fisco.

A Tabela 18 evidencia quantos entrevistados estão dispostos a pagar por um serviço de contabilidade qualificado, destinado a auxiliar na gestão, controle e administração das propriedades rurais.

Tabela 18 - Aceitação da contabilidade como uma prestação de serviço

\begin{tabular}{l|c|c}
\hline Pagaria por um Serviço de Contabilidade & Frequência Absoluta & Frequência Relativa (\%) \\
\hline Sim & 34 & 23 \\
Não & 116 & 77 \\
\hline Total & 150 & 100 \\
\hline
\end{tabular}

Fonte: Dados da pesquisa

Observou-se que os produtores rurais ainda não estão plenamente convictos de que a contabilidade pode ser um aliado para o agronegócio, pois, conforme a Tabela 18, 77\% dos entrevistados responderam que não pagariam pelo serviço, e apenas $23 \%$ estão dispostos pagar pelo serviço.

Em relação à avaliação da satisfação dos produtores rurais com as atividades que desenvolvem no meio rural, os resultados estão demonstrados na Tabela 19. 
Tabela 19 - Avaliação da satisfação no meio rural

\begin{tabular}{l|c|c}
\hline \multicolumn{1}{c|}{ Avaliação da Satisfação } & Frequência Absoluta & Frequência Relativa (\%) \\
\hline Plenamente satisfeito $(10-8)$ & 19 & 13 \\
Satisfeito $(8-6)$ & 103 & 69 \\
Insatisfeito $(6-4)$ & 28 & 0 \\
Totalmente insatisfeito (4 ou menos) & 0 & 190 \\
\hline Total & 150 & 0 \\
\hline
\end{tabular}

Fonte: Dados da pesquisa

Conforme os resultados constantes na Tabela 19, 13\% dos sujeitos pesquisados consideram-se plenamente satisfeitos com as atividades que desenvolvem no meio rural, 69\% consideram-se satisfeitos e outros 19\% afirmam estar insatisfeitos. A insatisfação pode gerar abandono de algumas atividades no meio rural ou até mesmo a migração para o meio urbano.

De modo geral o estudo contribui com o estudo de Zanchet e Francischetti Junior (2006), pois em ambos os estudos percebe-se que a maioria dos entrevistados não separa as suas despesas particulares com as dos gastos com aqueles das atividades desenvolvidas.

O estudo também corrobora com o estudo de Hofer, Borilli e Philippsen (2006), em que novamente, se percebe que a contabilidade é uma ferramenta pouco utilizada pelos proprietários rurais entrevistados. Neste estudo apenas $5 \%$ dos entrevistados afirmam utilizar a contabilidade em suas propriedades, assim como no estudo anterior, em que 5,34\% dos entrevistados que têm assessoria contábil.

Comparando-se com o estudo de Mazzioni et al. (2007), em ambas as regiões pesquisadas constatou-se a predominância de pequenas propriedades rurais. $\mathrm{O}$ estudo constatou-se que $77 \%$ dos entrevistados não possuem trabalhadores contratados em suas propriedades, similar aos resultados de Mazzioni et al. (2007) em que 78\% também não possuíam contratações.

Em relação ao faturamento, 33\% dos entrevistados possuem faturamento bruto anual de até $R \$ 12.000,00$, e $34 \%$ entre $R \$ 12.000,00$ e $R \$ 24.000,00$, situação similar encontrada no estudo de Mazzioni et al. (2007), em que 29\% dos entrevistados possuíam faturamento de até $\mathrm{R} \$ 12.000,00$, e $41 \%$ faturamento entre $\mathrm{R} \$ 12.000,00$ e $\mathrm{R} \$$ $24.000,00$. Constatou-se, em ambos os estudos, que não há separação das despesas particulares com as dos gastos do agronegócio: $61 \%$ neste estudo e $86 \%$ em Mazzioni et al. (2007).

De modo geral, os resultados reforçam que a agricultura familiar é praticada majoritariamente pelos próprios componentes da família, com baixa presença de mão-de-obra contratada. As propriedades são pequenas em extensão, com diversificação de atividades e o uso da contabilidade é muito baixa. 


\section{CONSIDERAÇÕES FINAIS}

Os resultados do estudo indicam que a amostra investiga é constituída, majoritariamente, por pequenos agricultores familiares sem utilização de mão-deobra terceirizada. As propriedades e áreas cultivadas são pequenas (menores de 15 há) e 2/3 das famílias produzem receitas inferiores a vinte e quatro mil Reais anuais.

O uso da contabilidade como instrumento de gestão das propriedades é bastante frágil, verificando-se níveis elevados de desconhecimento dos custos específicos de cada unidade produzida, falta de controles e relatórios para decisões e falta de segregação das despesas particulares daquelas relativas à atividade econômica.

Um dos possíveis fatores explicativos para a inexistência de controles gerenciais deve-se ao fato da contabilidade não ser obrigatória para os produtores rurais que possuem entidades com o nível de faturamento indicado pela maioria da amostra investigada. Os produtores rurais podem declarar seus resultados por meio da declaração de imposto de renda pessoa física, logo a não exigência fiscal e tributária pode interferir na busca pela utilização da contabilidade.

Os achados evidenciam que os produtores rurais pesquisados não fazem o uso da contabilidade e de seus relatórios e, consequentemente, a maioria não separa os gastos particulares dos gastos com a atividade rural, bem como, não fazem o uso da contabilidade como instrumento de apoio e controle para o processo de gestão dos estabelecimentos rurais.

A realidade verificada na pesquisa demonstra uma fragilidade de gestão em desobediência ao princípio da entidade, ao não segregar as operações dos negócios com aquelas dos proprietários do negócio. Além disso, parcela significativa dos pesquisados desconhecem as finalidades da contabilidade e não estão dispostos a pagar pelos serviços contábeis. Em decorrência dessa situação, é possível inferir que a condução dos negócios fica fragilizada e as decisões operacionais e de investimentos não são suportadas em critérios efetivos, mas pautadas na informalidade.

Em um ambiente de negócios tão dinâmico quanto o constatado no momento atual, decisões sem o amparo de informações fidedignas das condições econômicas e financeiras podem produzir resultados indesejados aos empreendimentos. Isso é ainda mais delicado quando apenas $7 \%$ dos produtores tem a condição de estabelecer preços de vendas. Ou seja, com a necessidade de acatar preços definidos por terceiros, é imperioso um controle efetivo dos custos e despesas que compõem cada produto para verificar a viabilidade de desenvolver determinada atividade, substituir por outra ou descontinuar. 
Os resultados da pesquisa evidenciam, de modo geral, a necessidade da utilização da contabilidade no meio rural. Inicialmente no sentido do seu reconhecimento e objetivos pelos gestores rurais e, posteriormente, como instrumento de apoio ao processo de gestão dos custos, avaliação dos resultados, para investimentos e embasamento das demais decisões. Contudo, os níveis de faturamento de uma porção importante de proprietários rurais pesquisados mostram-se restritivos para incorporar os custos com serviços contábeis.

Assim, entende-se que há um espaço para as entidades de classe contábil buscar parcerias com as entidades rurais de produtores, no sentido de viabilizar a assessoria de profissional contábil para melhorar a gestão dos estabelecimentos e, por extensão, a busca por melhor desempenho econômico e financeiro.

Recomendam-se novos estudos sobre a importância da utilização da contabilidade rural, sob o argumento que seu uso desta pode trazer benefícios para a gestão das atividades rurais.

\section{REFERÊNCIAS}

CALGARO, N. C.; FACCIN, K. Controle financeiro em propriedades rurais: estudos de caso do $3^{\circ}$ Distrito de Flores da Cunha. Global Manager Acadêmica, v. 1, n. 1, p.1-20, 2012.

CLEMENTE, A.; SOUZA, A.; TAFFAREL, M.; GERIGK, W. Perfil das propriedades rurais familiares e controle de custos na região centro-sul do Paraná. Custos e Agronegócio Online, v. 6, n. 3, p. 21-43, 2010.

CPC. COMITÊ DE PRONUNCIAMENTOS CONTÁBEIS. Pronunciamento técnico CPC 29 ativos biológicos e produtos agrícolas. Dispõem sobre o tratamento contábil dos ativos biológicos e produtos agrícolas. Disponível em: $<$ http://www.cpc.org.br/mostraOrientacao.php?id=45>. Acesso em: 18 ago. 2012.

CREPALDI, S. A. Contabilidade rural: uma abordagem decisorial. 6. ed. São Paulo: Atlas, 2011.

DORR, A. C.; GUSE, J. C.; FREITAS, L. A. R.; ROSSATO, M. V. Utilização de instrumentos de gestão contábil pelos produtores agropecuários. Revista Eletrônica de Contabilidade, v. 6, n.1, p. 35-45, 2012. 
FRANCISCHETTI JUNIOR, S. C.; ZANCHET, A. Perfil contábil-administrativo dos produtores rurais e a demanda por informações contábeis. Ciências Sociais e Aplicadas em Revista, v. 6, n. 11, p.1-18, 2006.

HOFER, E.; BORILli, S. P.; PHILIPPSEN, R. B. Contabilidade como ferramenta gerencial para a atividade rural: um estudo de caso. Enfoque: Reflexão Contábil, v. 25, n. 3, p. 5-16, 2006.

IBGE. INSTITUTO BRASILEIRO DE GEOGRAFIA E ESTATÍSTICA. Produção da pecuária municipal 2010. Disponível em: <http://www.ibge.gov.br/home/estatistica/economia/ppm/2010/ppm2010.pdf>.

Acesso em: 01 nov. 2012.

IUDÍCIBUS, S.; MARTINS, E.; GELBCKE, E. R.; SANTOS, A. Manual de contabilidade societária: aplicável a todas as sociedades de acordo com as normas internacionais e do CPC. São Paulo: Atlas, 2010.

MARION, J. C. Contabilidade rural: contabilidade agrícola, contabilidade da pecuária, imposto de renda - pessoa jurídica. 12. ed. São Paulo: Atlas, 2010.

MAZZIONI, S.; ZANIN, A.; KRUGER, S. D.; ROCHA, J. L. K. A importância dos controles gerenciais para o agribusiness. Revista Catarinense da Ciência Contábil, v. 6, p. 9-26, 2007.

MENDONÇA, C. Agronegócio: atividade alavanca exportações do Brasil. Disponível em: $\quad<$ http://educacao.uol.com.br/disciplinas/geografia/agronegocio-atividadealavanca-exportacoes-do-brasil.htm>. Acesso em: 30 out. 2012.

MIOR, L. C. Agricultores familiares, agroindústrias e redes de desenvolvimento rural. Chapecó: Argos, 2005

MDA. MINISTÉRIO DO DESENVOLVIMENTO AGRÁRIO. Ministro debate papel da agricultura familiar e oportunidade de negócios no RS. Disponível em: $<$ http://www.mda.gov.br/portal/noticias/item?item_id=10315050>. Acesso em 02 out. 2012.

O agronegócio familiar no Brasil e nos seus estados. Disponível em: http://portal.mda.gov.br/portal/saf/arquivos/view/ater/livros/O_Agroneg\%C3\%B3cio _Familiar_no_Brasil_e_nos_seus_Estados.doc.. Acesso em: 01 nov. 2012. 
OLIVEIRA, N. C. Contabilidade do agronegócio: teoria e prática. 2. ed. Curitiba: Juruá, 2010.

PLAIS, P. M. Os impactos da nova metodologia de contabilização no Brasil, dos ativos biológicos e dos derivativos (futuros) sobre os principais indicadores utilizados nas análises econômico-financeiras feitas por instituições financeiras para fins de financiamento de empresas do setor de commodities agrícolas. Revista de Finanças Aplicadas, v. 1, p.1-17, 2010.

RODRIGUES, A. O.; BUSCH, C. M.; GARCIA, E. R.; TODA, W. H. A nova contabilidade rural. São Paulo: IOB, 2011. 